\title{
First Trimester Pregnancy Loss May Temporary Reduce the Ovarian Response during the Subsequent IVF Cycle
}

\author{
Dina Levitas $^{1^{*}}$, Avi Harlev ${ }^{1 *}$, Michael Friger ${ }^{2}$, Iris Har-Vardi ${ }^{1}$, Atif Zeadna $^{1}$, Eliahu Levitas ${ }^{1 \#}$ \\ ${ }^{1}$ Fertility and IVF Unit, Department Of Obstetrics and Gynecology, Faculty of Health Sciences, Soroka Medical Center, \\ Beer-Sheva, Israel \\ ${ }^{2}$ Department of Epidemiology, Ben-Gurion University of the Negev, Beer-Sheva, Israel \\ Email: "Levitase@bgu.ac.il
}

How to cite this paper: Levitas, D., Harlev, A., Friger, M., Har-Vardi, I., Zeadna, A. and Levitas, E. (2018) First Trimester Pregnancy Loss May Temporary Reduce the Ovarian Response during the Subsequent IVF Cycle. Open Journal of Obstetrics and Gynecology, 8, 344-353.

https://doi.org/10.4236/ojog.2018.84038

Received: February 20, 2018

Accepted: April 10, 2018

Published: April 13, 2018

Copyright (c) 2018 by authors and Scientific Research Publishing Inc. This work is licensed under the Creative Commons Attribution International License (CC BY 4.0).

http://creativecommons.org/licenses/by/4.0/

\begin{abstract}
The aim of this study was to compare the in vitro fertilization (IVF) cycles ended by miscarriage with subsequent IVF cycles in relation to various IVF cycle parameters and pregnancy termination modalities. Comparison of pre-miscarriage to post-miscarriage IVF cycles parameters demonstrated that lower peak $\mathrm{E}_{2}$ levels $(1087 \pm 593$ versus $1237 \pm 676 \mathrm{pg} / \mathrm{ml}$, respectively; $p<0.05)$ were achieved in the post miscarriage cycles despite higher total gonadotropin consumption $(2341 \pm 1488$ versus $2115 \pm 1101 \mathrm{IU} ; p<0.05)$. A greater endometrial thickness $(10.4 \pm 2.16$ versus $9.98 \pm 1.74 \mathrm{~mm}$, respectively; $p<0.05)$ and a higher number of embryos $(4.62 \pm 2.63$ versus $3.78 \pm 2.54$, respectively; $p<0.05)$ were observed in the pre-miscarriage cycles. A comparison of IVF parameters between the first and second IVF cycles following miscarriage showed an increase in peak estradiol level (954 \pm 800 and $1257 \pm 838 \mathrm{pg} / \mathrm{ml}$, respectively; $p$ $<0.05)$, an increased number of retrieved oocytes $(7.38 \pm 4.2$ and $10.49 \pm 4.99$, respectively; $p<0.05)$, more fertilized embryos $(3.87 \pm 2.38$ and $5.66 \pm 3.64$, respectively; $p<0.05)$, and an increase in the conception rate $(34.7 \%$ versus $42.2 \%$, respectively) at the second post-miscarriage IVF cycle.
\end{abstract}

\section{Keywords}

IVF, Miscarriage, First Trimester Pregnancy Loss, Superovulation, Ovarian Response, Endometrial Thickness, Conception Rates

\section{Introduction}

Approximately $5 \%$ of in vitro fertilization (IVF) cycles end with an early preg-

${ }^{\star}$ Equally contributing author. 
nancy loss, representing $15 \%$ of pregnancies occurring after IVF [1]. The true incidence of miscarriage, however, is not well established as many of the pregnancy losses occur before pregnancy can be clinically recognized. After fertility treatment and particularly after IVF treatment, the diagnosis of pregnancy is made at an early stage compared to spontaneous pregnancies. Most women who undergo fertility treatment are highly motivated to have a pregnancy follow up at an early stage of the pregnancy, whereas data from spontaneous pregnancies is difficult to ascertain. There is no solid data to compare the incidence of miscarriage in spontaneous versus IVF pregnancies, but it is generally accepted that the incidence of miscarriage is slightly higher after IVF treatment [2] [3]. Little is known about the significance of prior early pregnancy loss on future IVF cycles. The literature contains conflicting data concerning the prognostic value of an early permanency loss on subsequent IVF cycles, some reported higher success rates after first trimester miscarriage during the next IVF attempt [4] [5]. Younger maternal age, premature rupture of membranes, intra-uterine growth restriction, hypertensive disorders, and preeclampsia are all independently associated with an initial miscarriage [6].

Once a spontaneous pregnancy loss has been diagnosed, there are three forms of management: expectant, medical, or surgical. The optimal mode of management is determined by gestational age, whether the pregnancy loss is delayed or incomplete, maternal hemodynamic stability, infection, and most importantly patient preference. Surgical management involves sharp curettage, vacuum aspiration, or a combination of both [7]. It is used in $80 \%$ of the cases, and considered the most common procedure used to manage spontaneous miscarriages. There is controversy about the complications after a surgical management. While some say that surgical management increases the risk of obstetrical complications and adverse perinatal outcomes [6], other studies show no evidence of such [8]. Medical management is an excellent alternative for women desiring minimal intervention. Such management is successful in $66 \%$ to $99 \%$ of women with incomplete or delayed pregnancy loss in the first trimester. Medical treatment typically begins with misoprostol, a prostaglandin E1 analog, whereas some regimens include mifepristone (a progesterone receptor antagonist) in combination with misoprostol [7]. Although little is known about the post-medical miscarriage complications, there are still controversies in different studies. Some studies show an increase of ectopic pregnancies [9], while others show no difference between medical and surgical termination of pregnancy [8] [9].

The objective of the present study was to address the widespread discrepancy of outcomes of IVF cycles after miscarriages and to investigate the impact of medical, surgical, and expectant miscarriage management after IVF on the subsequent IVF treatment outcome.

\section{Methods and Patients}

The present retrospective cohort study included data from 138 women who had a first trimester pregnancy loss following IVF. In this particular patient popula- 
tion, 417 IVF cycles prior to and post-miscarriage that occurred between the years 2004 and 2016 have been analyzed. The data was retrieved from patient charts at Soroka University Medical Center, analyzed, compared, and included in the study. The study was approved by the local Institutional Ethics Committee.

Cycles that ended with chemical miscarriages, late miscarriages, ectopic pregnancies, and patients with recurrent pregnancy loss were excluded from the study.

The miscarried 138 IVF cycles were categorized by the mode with which the pregnancies were managed: 81-surgically terminated (sharp curettage), 13-medically terminated, and 44 pregnancies-managed expectantly without intervention. The following patient characteristics have been retrieved and compared: patient age, spouse's age, basic hormonal levels, smoking, BMI.

The 417 IVF cycles, namely 181 prior to and 236 IVF cycles subsequent to the miscarriage have been analyzed according to the mode by which the miscarriage was approached. The group of surgical curettage $(\mathrm{n}=250)$ was subdivided into 103 prior and 147 post-curettage IVF cycles. The medically managed group ( $\mathrm{n}=$ 36) was subdivided into 17 prior and 19 post-miscarriage IVF cycles, and expectantly managed category $(\mathrm{n}=131)$ cycles subdivided into 61 prior and 70 post-miscarriage IVF cycles.

The following IVF cycle parameters have been compared between the pre-miscarriage and post-miscarriage cycles: endometrial thickness, peak estradiol $\left(\mathrm{E}_{2}\right)$ levels, total gonadotropin consumption per cycle, number of oocytes retrieved, number of fertilized eggs, number of cleavage embryos. Ovarian response was further assessed using the ovarian sensitivity index (OSI) [10]. OSI is the ratio between aspirated oocytes and total dose of FSH used in the cycle.

\section{Data Analysis}

Statistical analyses were performed using the Statistical Package for Social Sciences (version 21, SPSS Inc.). All tests were two tailed, and statistical significance was set at $p<0.05$. Continuous variables are presented as means and were tested by independent t-test or One-Way ANOVA. Categorical variables comparison was performed by Chi-square test. Multivariate logistic regression was used to characterize the IVF cycle characteristics pre- and post-miscarriage while neutralizing confounding factors such as maternal age, paternal age, ethnicity, smoking, and BMI.

\section{Results}

Comparing patient criteria including maternal age, paternal age, BMI, smoking, and levels of FSH, LH, and TSH did not demonstrate any statistically significant differences between those who have been managed surgically, medically, or expectantly (Table 1). 
Table 1. Patient characteristics according to the mode of pregnancy termination.

\begin{tabular}{cccccc}
\hline Mean \pm SD & $\begin{array}{c}\text { Total Patients } \\
\mathrm{N}=138\end{array}$ & $\begin{array}{c}\text { Surgical } \\
\mathrm{N}=81\end{array}$ & $\begin{array}{c}\text { Medical } \\
\mathrm{N}=13\end{array}$ & $\begin{array}{c}\text { Expectant } \\
\mathrm{N}=44\end{array}$ & $p$ value \\
\hline Maternal age (y) & $31.52 \pm 5.26$ & $32.19 \pm 5.39$ & $32.35 \pm 5.84$ & $30.06 \pm 4.67$ & 0.162 \\
Paternal age (y) & $35.17 \pm 7.23$ & $35.87 \pm 7.80$ & $35.58 \pm 8.14$ & $33.83 \pm 5.73$ & 0.361 \\
BMI & $26.16 \pm 6.58$ & $26.22 \pm 6.27$ & $27.11 \pm 8.76$ & $25.77 \pm 6.35$ & 0.581 \\
FSH (IU) & $6.85 \pm 2.21$ & $6.86 \pm 2.32$ & $7.59 \pm 2.70$ & $6.64 \pm 1.85$ & 0.563 \\
LH (IU) & $6.37 \pm 5.85$ & $7.39 \pm 7.31$ & $5.25 \pm 2.50$ & $4.91 \pm 2.30$ & 0.127 \\
TSH (mIU) & $2.47 \pm 1.27$ & $2.67 \pm 1.38$ & $2.55 \pm 1.58$ & $2.07 \pm .80$ & 0.076 \\
\hline
\end{tabular}

Gestational age at the time of pregnancy termination in the abortion pregnancy significantly differed between the various pregnancy termination modes i.e. surgical, medical and complete abortions $(10.38 \pm 4.37,7.85 \pm 1.36$, and 6.85 \pm 3.95 respectively, $p<0.01$ ). IVF protocols and the type of gonadotropins used were comparable between study groups. Analyzing all IVF cycles included in the study (Table 2) regardless of the mode of pregnancy termination, showed that mean endometrial thickness among the 181 IVF cycles prior to the miscarriage was significantly higher compared with the 236 IVF cycles that followed the miscarriage (10.47 \pm 2.16 and $9.98 \pm 1.74 \mathrm{~mm}$, respectively; $p=0.003)$. Furthermore, the peak estradiol level was found to be higher in the pre-miscarriage compared with post-miscarriage cycles (1237.20 \pm 676.29 and $1087.71 \pm 593.26$ $\mathrm{pg} / \mathrm{ml}$, respectively; $p<0.05)$ despite a lower gonadotropin consumption per cycle for the pre-miscarriage cycle $(2115 \pm 1107$ and $2341 \pm 1488$ IU, respectively; $p<0.05)$. Although the number of oocytes retrieved was similar, the number of embryos available for transfer was higher in cycles prior to the miscarriage compared with the post-miscarriage cycles $(4.62 \pm 2.63$ and $3.78 \pm 2.54$, respectively; $p<0.05)$. Comparing the OSI in the pre- and post-miscarriage cycles, a non-significant increased OSI was noted in the post miscarriage cycle $(4.413 \pm$ 3.49 vs. $4.741 \pm 3.64$ respectively, $p=0.509)$. However, comparing the post miscarriage cycle to the subsequent one, a significant OSI increase was noted (4.058 \pm 3.04 vs. $5.982 \pm 5.04$ respectively, $p=0.012$ ).

Interestingly, analyzing the IVF cycles according to the mode of pregnancy termination has shown the endometrial thickness to not be significantly affected by medical or expectant management of the miscarriages. Surgical termination of pregnancies disclosed a statistically significant reduction of endometrial thickness comparing the pre-miscarriage and the post-miscarriage cycles data (10.79 \pm 2.13 and $10.13 \pm 1.68 \mathrm{~mm}$, respectively; $p<0.05$ ). Although the mean total gonadotropin consumption per cycle was found to be lower in the pre-miscarriage IVF cycles, the number of embryos available for transfer was higher in the pre-miscarriage cycles compared with the post-miscarriage cycles, even though the data did not reach statistical significance (Table 2).

Using multiple logistic regression analysis, controlling for women's age and confounders related to the post-miscarriage IVF cycles, such as peak estradiol 
Table 2. Comparison of IVF cycle parameters between cycles prior to and following first trimester pregnancy loss related to the mode of pregnancy termination.

\begin{tabular}{|c|c|c|c|c|c|c|c|}
\hline $\begin{array}{l}\text { Miscarriage } \\
\text { management }\end{array}$ & IVF cycles & $\begin{array}{c}\text { Endometrial } \\
\text { thickness (mm) }\end{array}$ & $\begin{array}{l}\text { Peak } E_{2} \\
(\mathrm{pg} \backslash \mathrm{ml})\end{array}$ & $\begin{array}{l}\text { Total gonadotropins } \\
\text { per cycle (IU) }\end{array}$ & $\begin{array}{l}\text { Number } \\
\text { of oocytes }\end{array}$ & $\begin{array}{c}\text { Number of } \\
\text { fertilized oocytes }\end{array}$ & $\begin{array}{c}\text { Number of } \\
\text { embryos }\end{array}$ \\
\hline & $\begin{array}{l}\text { Pre-miscarriage } \\
\quad \mathrm{n}=181\end{array}$ & $10.47 \pm 2.16$ & $1237 \pm 676$ & $2115 \pm 1101$ & $9.2 \pm 4.7$ & $5.39 \pm 2.97$ & $4.62 \pm 2.63$ \\
\hline Total IVF cycles & $\begin{array}{l}\text { Post-miscarriage } \\
\qquad \mathrm{n}=236\end{array}$ & $9.98 \pm 1.74$ & $1087 \pm 593$ & $2341 \pm 1488$ & $9.08 \pm 5.61$ & $5.19 \pm 3.78$ & $3.78 \pm 2.54$ \\
\hline \multirow[t]{2}{*}{$\mathrm{n}=417$} & $p$ & 0.003 & 0.041 & 0.026 & 0.808 & 0.583 & 0.006 \\
\hline & $\begin{array}{l}\text { Pre-miscarriage } \\
\quad \mathrm{n}=103\end{array}$ & $10.79 \pm 2.13$ & $1229 \pm 694$ & $2183 \pm 1056$ & $8.7 \pm 4.58$ & $5.07 \pm 2.97$ & $4.6 \pm 2.65$ \\
\hline \multirow[t]{3}{*}{$\begin{array}{l}\text { Surgical } \\
n=250\end{array}$} & $\begin{array}{l}\text { Post-miscarriage } \\
\qquad \mathrm{n}=147\end{array}$ & $10.13 \pm 1.68$ & $1168 \pm 580$ & $2458 \pm 1675$ & $9.36 \pm 6.3$ & $5.3 \pm 4.32$ & $4.06 \pm 2.92$ \\
\hline & $p$ & 0.001 & 0.868 & 0.052 & 0.238 & 0.517 & 0.224 \\
\hline & $\begin{array}{l}\text { Pre-miscarriage } \\
\quad \mathrm{n}=17\end{array}$ & $9.67 \pm 1.78$ & $1306 \pm 366$ & $1364 \pm 781$ & $10.78 \pm 5.45$ & $5.35 \pm 2.07$ & $4.61 \pm 1.83$ \\
\hline \multirow[t]{3}{*}{$\begin{array}{l}\text { Medical } \\
\mathrm{n}=36\end{array}$} & $\begin{array}{l}\text { Post-miscarriage } \\
\qquad \mathrm{n}=19\end{array}$ & $9.41 \pm 1.65$ & $657 \pm 375$ & $1883 \pm 1078$ & $7.71 \pm 3.9$ & $5.42 \pm 3.15$ & $2.88 \pm 1.48$ \\
\hline & $p$ & 0.741 & 0.004 & 0.063 & 0.064 & 0.776 & 0.054 \\
\hline & $\begin{array}{l}\text { Pre-miscarriage } \\
\quad n=61\end{array}$ & $10.25 \pm 2.12$ & $1029 \pm 724$ & $2139 \pm 1218$ & $9.9 \pm 4.77$ & $6.06 \pm 3.1$ & $4.53 \pm 2.69$ \\
\hline \multirow[t]{2}{*}{$\begin{array}{l}\text { Expect } \\
n=131\end{array}$} & $\begin{array}{l}\text { Post-miscarriage } \\
\qquad \mathrm{n}=70\end{array}$ & $10.0 \pm 1.67$ & $1026 \pm 584$ & $2194 \pm 1091$ & $8.8 \pm 4.31$ & $4.91 \pm 2.6$ & $3.59 \pm 1.95$ \\
\hline & $p$ & 0.435 & 0.049 & 0.557 & 0.113 & 0.016 & 0.052 \\
\hline
\end{tabular}

$\left(\mathrm{E}_{2}\right)$ level, total gonadotropin consumption, number of oocytes retrieved, and number of embryos obtained, only peak $\mathrm{E}_{2}$ level was significantly associated with a reduced clinical pregnancy rate in post-miscarriage IVF cycles (OR 1.001, CI $1.000-1.001, p=0.007)$.

Comparison of IVF parameters between the first $(\mathrm{n}=138)$ and second $(\mathrm{n}=$ 90) cycles following the miscarriage has shown (Table 3) comparable endometrial thickness between the first and the second post-miscarriage cycles with a significantly increasing peak $\mathrm{E}_{2}$ level $(954 \pm 800.39$ and $1257 \pm 838 \mathrm{pg} / \mathrm{ml}$, respectively; $p<0.05)$, more retrieved oocytes $(7.38 \pm 4.2$ and $10.49 \pm 4.99$, respectively; $p<0.05)$, and more fertilized oocytes $(3.53 \pm 2.74$ and $4.28 \pm 3.11$, respectively; $p<0.05$ ), despite a comparable total amount of injected gonadotropins, emphasizing an improved response of the ovaries to gonadotropin treatment. Most importantly, an increased conception rate was obtained among the patients undergoing the second IVF cycle following miscarriage compared with the first post-miscarriage cycle ( $42.2 \%$ versus $34.7 \%$, respectively). The time frame to the first post-miscarriage IVF was $44-577$ days (mean 202.2) and the time frame to the second IVF was $162-590$ days (mean 424.7).

\section{Discussion}

Spontaneous miscarriage refers to a pregnancy that ends spontaneously before 
Table 3. Comparison of IVF parameters between the first and the second IVF cycles following pregnancy loss.

\begin{tabular}{|c|c|c|c|c|c|c|c|c|c|}
\hline $\begin{array}{l}\text { IVF cycles } \\
\text { following } \\
\text { miscarriage }\end{array}$ & $\begin{array}{l}\text { Mean Interval } \\
\text { from miscarriage } \\
\text { to conception } \\
\text { (range in days) }\end{array}$ & $\begin{array}{l}\text { Endometrial } \\
\text { thickness } \\
(\mathrm{mm})\end{array}$ & $\begin{array}{c}\text { Peak } E_{2} \\
(\mathrm{pg} / \mathrm{ml})\end{array}$ & $\begin{array}{c}\text { Total } \\
\text { gonadotropins } \\
\text { per cycle (IU) }\end{array}$ & $\begin{array}{c}\text { Number of } \\
\text { oocytes }\end{array}$ & OSI & $\begin{array}{c}\text { Number of } \\
\text { fertilized } \\
\text { oocytes }\end{array}$ & $\begin{array}{l}\text { Number } \\
\text { of } \\
\text { embryos }\end{array}$ & Pregnancies \\
\hline $\begin{array}{c}\text { First cycle } \\
n=138\end{array}$ & $\begin{array}{c}202.2 \\
(44-577)\end{array}$ & $9.93 \pm 1.96$ & $954 \pm 800$ & $2396 \pm 1252$ & $7.38 \pm 4.2$ & $4.058 \pm 3.04$ & $3.87 \pm 2.38$ & $3.53 \pm 2.74$ & $48(34.7 \%)$ \\
\hline $\begin{array}{c}\text { Second cycle } \\
\mathrm{n}=90\end{array}$ & $\begin{array}{c}424.7 \\
(162-590)\end{array}$ & $10.05 \pm 2.05$ & $1257 \pm 838$ & $2415 \pm 1369$ & $10.49 \pm 4.99$ & $5.982 \pm 5.04$ & $5.66 \pm 3.64$ & $4.28 \pm 3.11$ & $38(42.2 \%)$ \\
\hline$p$ & & 0.552 & 0.623 & 0.898 & 0.001 & $<0.001$ & 0.013 & 0.088 & 0.386 \\
\hline
\end{tabular}

the fetus has reached a viable gestational age. In the majority of cases, single, sporadic, and spontaneous miscarriages have traditionally been attributed to chromosomal abnormalities. However, if chromosomal abnormalities are not the miscarriage cause, other multi-factorial etiologies may be the miscarriage underlying cause. Women with an initial miscarriage have an increased risk for obstetrical complications and adverse perinatal outcomes compared with women with a previous delivery beyond 22 weeks' gestation [7] [11]. The consequences of the miscarriage may impact the subsequent IVF cycle. That was the basis for the current study, addressing these possible impacts such as ovarian response and endometrial thickness among others.

Surprisingly, we have discovered a significantly reduced peak estradiol levels as well as a reduced number of embryos available for transfer, in spite of an increased consumption of total gonadotropins per cycle in the post-miscarriage compared with the pre-miscarriage IVF cycles. Based on our observation, the reduced ovarian response seems to be temporary and still partially present 6 months post-miscarriage with a full recovery observed about 14 months post-miscarriage. The parameters of the ovarian response, such as peak estradiol level, number of oocytes retrieved, OSI and number of fertilized embryos, were significantly increased in the second post-miscarriage cycle compared with the first cycle. In fact, the pregnancy rates were found to be higher among patients having the second post-miscarriage IVF cycle compared with the first post-miscarriage IVF.

It is accepted that a thickening of the endometrium is critical to a successful implantation of embryos in the uterine cavity. There is controversy regarding the clinical significance in variations of endometrial thickness observed among patients undergoing IVF and the association of the endometrial thickness with the conception rates after IVF and ET. It is widely accepted that an adequate thickness of endometrium is indispensable for a successful pregnancy in ART cycles [12]. It is generally accepted that pregnancy does not occur when the endometrium measures $<7 \mathrm{~mm}$. Embryo implantation and clinical and ongoing pregnancy rates are significantly higher in patients with an endometrial thickness $\geq 9-10 \mathrm{~mm}$ [13]. It was observed that when the endometrial thickness is 14 $\mathrm{mm}$ and more, the pregnancy rates were significantly lower, and also suggests a 
possible increase in spontaneous miscarriage rate [12] [14]. Endometrial thickness is measured in the mid-sagittal plane during transvaginal ultrasound, which is considered both non-traumatic and simple [15].

Many authors suggest a positive relationship between endometrial thickness and pregnancy rates in either autologous or donor oocytes [16] [17] [18] [19]. Significantly higher conception rates have been observed with thicker endometrium in autologous or donor oocytes after IVF cycles [20] [21] [22] [23].

One of the strategies to distinguish between ovarian and uterine factors is to evaluate the results among patients using donated oocytes. Studies have found endometrial thickness to be predictive of the pregnancy rates in patients treated with donor oocytes [22]. Such studies provide further support for the conclusion that endometrial thickness is indicative of endometrial receptivity.

Although our study has shown a statistically significant reduction of endometrial thickness following a miscarriage, particularly one involving surgical treatment, it seems clinically insignificant. Nevertheless, some studies suggest that the magnitude of endometrial thickness may be associated with the reduction of pregnancy rates [24] [25]. Authors such as Moon et al. [26] demonstrated the same results as ours regarding endometrial thickness post-dilatation and curettage with recovery of endometrial thickness 6 months post-miscarriage. There were more studies that indicated recovery over different periods of time [19] [20] [21]. An unsolved question is the mechanism of action for the endometrial thickness reduction. Given the reduced ovarian response resulting in lower estrogen levels, one might have thought that the lower estrogen levels reduce the endometrial thickness as estrogen is the hormone that causes the endometrial proliferation. However, as observed in thawed embryo transfers especially in natural cycles, even low levels of estrogen, much lower than estrogen levels in fresh cycles, produces good endometrial thickness and favored cycle outcomes. A possible mechanism is the mechanical impact of a surgical pregnancy termination. This pregnancy termination method did exhibit poorer endometrial thickness in the current study but further studies are still required to establish that association.

In addition, and based on our results, it cannot be excluded that more factors, besides endometrial thickness reduction, can play a role in reduced conception rates post-miscarriage. Therefore, we may speculate that the observed temporary reduction of the ovarian response to gonadotropin treatment and a reduced conception rate in the first IVF cycle following the miscarriage, and the improvement observed at the second IVF cycle following the miscarriage, regardless of a comparable endometrial thickness between the first and the second cycles, demonstrate a recovery of the ovarian response to gonadotropins.

The impact of a miscarriage on a subsequent IVF cycle has been previously studied with contradicting results. While some studies reported a pregnancy loss in IVF cycle as a prognostic factor for future pregnancies, others found that a pregnancy loss does not negatively affect the outcome of the subsequent cycle 
and even one suggested it to be a positive predictor [4]. The current study, did reveal an unreported impact on the subsequent cycles in the form of a temporarily reduced ovarian response along with an endometrial thickness reduction. The mechanism of action by which a pregnancy loss reduced the ovarian response is unclear. A possible mechanism may be an interrupted ovarian blood flow. It is well established that ovarian surgical interventions diminish the ovarian reserve and directly impacts subsequent ovarian response. The increased blood flow to the reproductive system via the uterine and possibly the ovarian artery was previously established. It may be estimated that a pregnancy loss deteriorates the increased blood flow maybe as a protective effect thus naturally reducing pregnancy rates via reduced ovarian response. This hypothesis should be further investigated.

The current study has some limitations. First and foremost is its retrospective design. Second, is the lack of information regarding the age of the transferred embryos. We have attempted to overcome these limitations using comprehensive data collection extracted from the Soroka IVF unit records, which were conducted by expert physicians. Also, being the sole medical center in the region in which all women undergoes the IVF cycle as well as the pregnancy surveillance and delivery, also strengthen the study.

Therefore, miscarriage may have a negative effect on endometrial thickness and on the ovarian response to gonadotropins and consequently the subsequent conception rates. We could not find such an observation published in the literature in support of or in contrast to our findings. Moreover, our study was able to distinguish between the detrimental effects of surgically managed miscarriage compared to a medical or spontaneous resolution of the miscarriage. The surgical approach to termination of a pregnancy was clearly related to a reduced endometrial thickness while the medical or spontaneous resolution had no impact on endometrial thickness.

\section{Comment}

We may conclude that medical termination or expectant management of an early pregnancy loss should be the preferred methods with the purpose to safeguard the endometrial ability to implant embryos in the near future. Miscarriage, regardless of the mode of pregnancy termination, will negatively affect the ovarian response to gonadotropin stimulation and the conception rate in the short term. Therefore, following miscarriage, the subsequent IVF cycle should be postponed at least 5 - 6 months with the purpose to regain endometrial receptivity and normalize the ovarian response to gonadotropins. More and large studies aimed to analyze the ovarian response in addition to endometrial thickness after early pregnancy loss are needed to corroborate our findings.

\section{Conflict}

There is no conflict of interest to be reported. 


\section{Support}

No financial support was received for this research study.

\section{References}

[1] Lin, M.H., Lee, R.K.-K., Li, S.H., Lu, C.H., Sun, F.J. and Hwu, Y.M. (2008) Sperm Chromatin Structure Assay Parameters Are Not Related to Fertilization Rates, Embryo Quality, and Pregnancy Rates in In Vitro Fertilization and Intracytoplasmic Sperm Injection, but Might Be Related to Spontaneous Abortion Rates. Fertility and Sterility, 90, 352-359. https://doi.org/10.1016/j.fertnstert.2007.06.018

[2] Tummers, P., De Sutter, P. and Dhont, M. (2003) Risk of Spontaneous Abortion in Singleton and Twin Pregnancies after IVF/ICSI. Human Reproduction, 18, 1720-1723. https://doi.org/10.1093/humrep/deg308

[3] Bates Jr., G.W. and Ginsburg, E.S. (2002) Early Pregnancy Loss in in vitro Fertilization (IVF) Is a Positive Predictor of Subsequent IVF Success. Fertility and Sterility, 77, 337-341. https://doi.org/10.1016/S0015-0282(01)02988-0

[4] Haas, J., Lerner-Geva, L., Yerushalmi, G.M., Maman, E., Yinon, Y., Baum, M. and Hourvitz, A. (2012) Previous Abortion Is a Positive Predictor for Ongoing Pregnancy in the Next Cycle in Women with Repeated IVF Failures. Reproductive Biomedicine Online, 25, 339-344. https://doi.org/10.1016/j.rbmo.2012.06.020

[5] Kalu, E., Thum, M.Y. and Abdalla, H. (2011) Prognostic Value of First IVF Cycle on Success of a Subsequent Cycle. Journal of Assisted Reproduction and Genetics, 28, 379-382. https://doi.org/10.1007/s10815-010-9534-0

[6] McCarthy, F.P., Khashan, A.S., North, R.A., Rahma, M.B., Walker, J.J., Baker, P.N., Dekker, G., Poston, L., McCowan, L.M., O’Donoghue, K., Kenny, L.C. and SCOPE Consortium. (2013) Pregnancy Loss Managed by Cervical Dilatation and Curettage Increases the Risk of Spontaneous Preterm Birth. Human Reproduction, 28, 3197-3206. https://doi.org/10.1093/humrep/det332

[7] Allison, J.L., Sherwood, R.S. and Schust, D.J. (2011) Management of First Trimester Pregnancy Loss Can Be Safely Moved into the Office. Reviews in Obstetrics and Gynecology, 4, 5-14.

[8] Virk, J., Zhang, J. and Olsen, J. (2007) Medical Abortion and the Risk of Subsequent Adverse Pregnancy Outcomes. The New England Journal of Medicine, 357, 648-653. https://doi.org/10.1056/NEJMoa070445

[9] Bouyer, J., Coste, J., Shojaei, T., Pouly, J.L., Fernandez, H., Gerbaud, L. and Job-Spira, N. (2003) Risk Factors for Ectopic Pregnancy: A Comprehensive Analysis Based on a Large Case-Control, Population-Based Study in France. American Journal of Epidemiology, 15, 1851-1894. https://doi.org/10.1093/aje/kwf190

[10] Huber, M., Hadziosmanovic, N., Berglund, L. and Holte, J. (2013) Using the Ovarian Sensitivity Index to Define Poor, Normal, and High Response after Controlled Ovarian Hyperstimulation in the Long Gonadotropin-Releasing Hormone-Agonist Protocol: Suggestions for a New Principle to Solve an Old Problem. Fertility and Sterility, 100, 1270-1276. https://doi.org/10.1016/j.fertnstert.2013.06.049

[11] Weintraub, A.Y., Sergienko, R., Harlev, A., Holcberg, G., Mazor, M., Wiznitzer, A. and Sheiner, E. (2011) An Initial Miscarriage Is Associated with Adverse Pregnancy Outcomes in the Following Pregnancy. American Journal of Obstetrics and Gynecology, 205, 286. https://doi.org/10.1016/j.ajog.2011.06.053

[12] Aydin, T., Kara, M. and Nurettin, T. (2013) Relationship between Endometrial Thickness and In Vitro Fertilization-Intracytoplasmic Sperm Injection Outcome. International Journal of Fertility \& Sterility, 7, 29-34. 
[13] Revel, A. (2012) Defective Endometrial Receptivity. Fertility and Sterility, 97, 1028-1032. https://doi.org/10.1016/j.fertnstert.2012.03.039

[14] Richter, K.S., Bugge, K.R., Bromer, J.G. and Levy, M.J. (2007) Relationship between Endometrial Thickness and Embryo Implantation, Based on 1,294 Cycles of in vitro Fertilization with Transfer of Two Blastocyst-Stage Embryos. Fertility and Sterility, 87, 53-59. https://doi.org/10.1016/j.fertnstert.2006.05.064

[15] Al-Ghamdi, A., Coskun, S., Al-Hassan, S., Al-Rejjal, R. and Awartani, K. (2008) The Correlation between Endometrial Thickness and Outcome of in vitro Fertilization and Embryo Transfer (IVF-ET) Outcome. Reproductive Biology and Endocrinology, 6, 37. https://doi.org/10.1186/1477-7827-6-37

[16] Glissant, A., de Mouzon, J. and Frydman, R. (1985) Ultrasound Study of the Endometrium during in Vitro Fertilization Cycles. Fertility and Sterility, 44, 786-790. https://doi.org/10.1016/S0015-0282(16)49038-2

[17] Gonen, Y., Casper, R.F., Jacobson, W. and Blankier, J. (1989) Endometrial Thickness and Growth during Ovarian Stimulation: A Possible Predictor of Implantation in in Vitro Fertilization. Fertility and Sterility, 52, 446-450. https://doi.org/10.1016/S0015-0282(16)60916-0

[18] Kovacs, P., Matyas, S., Boda, K. and Kaali, S.G. (2003) The Effect of Endometrial Thickness on IVF/ICSI Outcome. Human Reproduction, 18, 2337-2341. https://doi.org/10.1093/humrep/deg461

[19] Abdalla, H.I., Brooks, A.A., Johnson, M.R., Kirkland, A., Thomas, A. and Studd, J.W. (1994) Endometrial Thickness: A Predictor of Implantation in Ovum Recipients? Human Reproduction, 9, 363-365.

[20] Zenke, U. and Chetkowski, R.J. (2004) Transfer and Uterine Factors Are the Major Recipient-Related Determinants of Success with Donor Eggs. Fertility and Sterility, 82, 850-856. https://doi.org/10.1016/j.fertnstert.2004.03.057

[21] Check, J.H., Nowroozi, K., Choe, J., Lurie, D. and Dietterich, C. (1993) The Effect of Endometrial Thickness and Echo Pattern on in Vitro Fertilization Outcome in Donor Oocyte-Embryo Transfer Cycle. Fertility and Sterility, 59, 72-75. https://doi.org/10.1016/S0015-0282(16)55617-9

[22] Noyes, N., Hampton, B.S., Berkeley, A., Licciardi, F., Grifo, J. and Krey, L. (2001) Factors Useful in Predicting the Success of Oocyte Donation: A 3-Year Retrospective Analysis. Fertility and Sterility, 76, 92-97. https://doi.org/10.1016/S0015-0282(01)01823-4

[23] Zhang, X., Chen, C.H., Confino, E., Barnes, R., Milad, M. and Kazer, R.R. (2005) Increased Endometrial Thickness Is Associated with Improved Treatment Outcome for Selected Patients Undergoing in Vitro Fertilization-Embryo Transfer. Fertility and Sterility, 83, 336-340. https://doi.org/10.1016/j.fertnstert.2004.09.020

[24] Sher, G., Dodge, S., Maassarani, G., Knutzen, V., Zouves, C. and Feinman, M. (1993) Management of Suboptimal Sonographic Endometrial Patterns in Patients Undergoing in-Vitro Fertilization and Embryo Transfer. Human Reproduction, 8, 347-349. https://doi.org/10.1093/oxfordjournals.humrep.a138049

[25] Weckstein, L.N., Jacobson, A., Galen, D., Hampton, K. and Hammel, J. (1997) Low-Dose Aspirin for Oocyte Donation Recipients with a Thin Endometrium: Prospective, Randomized Study. Fertility and Sterility, 68, 927-930. https://doi.org/10.1016/S0015-0282(97)00330-0

[26] Moon, K.S., Richter, K.S., Levy, M.J. and Widra, E.A. (2009) Does Dilation and Curettage versus Expectant Management for Spontaneous Abortion in Patients Undergoing in Vitro Fertilization Affect Subsequent Endometrial Development? Fertility and Sterility, 92, 1776-1779. https://doi.org/10.1016/j.fertnstert.2009.05.045 